\title{
Variation in Susceptibility of Bloodstream Isolates of Candida glabrata to Fluconazole According to Patient Age and Geographic Location
}

\author{
M. A. Pfaller, ${ }^{1,2 *}$ S. A. Messer, ${ }^{1}$ L. Boyken, ${ }^{1}$ S. Tendolkar, ${ }^{1}$ R. J. Hollis, ${ }^{1}$ and D. J. Diekema ${ }^{1,3}$ \\ Departments of Pathology ${ }^{1}$ and Medicine, ${ }^{3}$ Roy J. and Lucille A. Carver College of Medicine, and Department of \\ Epidemiology, College of Public Health, ${ }^{2}$ University of Iowa, Iowa City, Iowa 52242
}

Received 18 November 2002/Returned for modification 12 January 2003/Accepted 8 February 2003

\begin{abstract}
We examined the susceptibilities to fluconazole of 559 bloodstream infection isolates of Candida glabrata and grouped the isolates by patient age and geographic location within the United States. Susceptibility of $C$. glabrata to fluconazole was lowest in the Pacific (44\%) and East South Central $(47 \%)$ regions and was highest in the West South Central region (82\%) (regions are as designated by the U.S. Bureau of the Census). Isolates from pediatric patients were virtually all susceptible to fluconazole, whereas the highest frequency of resistance was observed in isolates from patients 16 to 64 years of age.
\end{abstract}

Candida glabrata is an increasingly common cause of bloodstream infection in hospitalized patients $(1,3,7,12,15,16,23)$. C. glabrata is innately less susceptible to fluconazole and amphotericin B than most other species of Candida $(13,17)$ and displays the capacity to rapidly develop resistance to all azoles via induction of the CDR efflux pumps $(20-22,25)$. Exposure of $C$. glabrata to subtherapeutic concentrations of fluconazole may result in resistance, and clinical studies have shown that the frequency of colonization and infection of patients with $C$. glabrata may be increased in populations subjected to fluconazole prophylaxis $(1,7,10,26)$. Additionally, the frequency of C. glabrata as a cause of bloodstream infection has been observed to increase with increasing patient age, although detailed studies of patients greater than 65 years of age are lacking $(6,8,14-16)$. The emergence of $C$. glabrata as an important bloodstream infection pathogen may not be a simple matter of selective pressure by a drug (e.g., fluconazole) but may also be influenced by patient age, underlying diseases, geographic location, or other unknown factors $(4,8,16,18,22)$.

The purpose of this study was to describe the variation in fluconazole susceptibility of C. glabrata bloodstream isolates stratified by patient age and geographic location in the United States.

Between 1992 and 2001, a total of 3,683 bloodstream isolates of Candida spp. from 167 medical centers in the United States were submitted to the University of Iowa College of Medicine (Iowa City) for identification and antifungal susceptibility testing with fluconazole. The isolates represented consecutiveincident isolates from patients with candidemia treated at hospitals within all nine U.S. Bureau of the Census regions (Table 1) (16). Patient ages were provided for 559 (83\%) of the 674 bloodstream isolates of C. glabrata. These 559 isolates constitute the study set described herein.

All C. glabrata isolates were identified using Vitek and API products (bioMerieux, Hazelwood, Mo.), the results with which were supplemented by conventional methods as re-

\footnotetext{
* Corresponding author. Mailing address: Medical Microbiology Division, C606 GH, Department of Pathology, University of Iowa College of Medicine, Iowa City, IA 52242. Phone: (319) 384-9566. Fax: (319) 356-4916. E-mail: michael-pfaller@uiowa.edu.
}

quired, and stored as water suspensions until they were used. Prior to testing, each isolate was passaged on potato dextrose agar (Remel, Lenexa, Kans.) and CHROMagar (Hardy Laboratories, Santa Monica, Calif.) to ensure purity and viability.

Fluconazole was obtained from the manufacturer (Pfizer, New York, N.Y.) as a standard reagent-grade powder. Broth microdilution testing was performed in accordance with the guidelines in NCCLS document M27-A (11). The interpretive criteria for fluconazole were those published by the NCCLS (11), as follows: an isolate for which the MIC is $\leq 8 \mu \mathrm{g} / \mathrm{ml}$ is susceptible, an isolate for which the MIC is 16 to $32 \mu \mathrm{g} / \mathrm{ml}$ is susceptible in a dose-dependent manner, and an isolate for which the MIC is $\geq 64 \mu \mathrm{g} / \mathrm{ml}$ is resistant.

Quality control was accomplished by testing the following strains: C. parapsilosis ATCC 22019 and C. krusei ATCC 6258 $(5,11)$.

Overall, C. glabrata accounted for $18.3 \%$ of all Candida sp. bloodstream isolates and was the second most common Candida sp. isolated. The frequency of C. glabrata as a cause of candidemia in the United States ranged from $11.7 \%$ in region 4 (West South Central) to $37.3 \%$ in region 7 (New England) (Table 1).

The fluconazole susceptibilities of $C$. glabrata bloodstream isolates varied by region (Table 2). Interestingly, there was no relationship between the prevalence of $C$. glabrata as a cause of bloodstream infection and the rate of resistance (MIC, $\geq 64$ $\mu \mathrm{g} / \mathrm{ml}$ ) to fluconazole; the region with the highest prevalence of C. glabrata (New England; 37.3\%) had the lowest frequency of resistance $(0 \%)$. The three regions with the highest percentage of resistance (regions 6, 7, and 9) were contiguous in the eastern and southeastern United States (Tables 1 and 2).

As expected from previous studies $(14,15,19)$, few bloodstream infections due to $C$. glabrata were reported from pediatric age groups ( $\leq 15$ years) (Table 2). Only 13 C. glabrata bloodstream isolates were submitted from patients $\leq 15$ years of age. Only 1 of the 13 was resistant to fluconazole. Fluconazole resistance was greatest among $C$. glabrata isolates from patients 16 to 64 years of age $(12 \%)$.

Although much has been written regarding the importance of fluconazole resistance among clinical isolates of $C$. glabrata $(3,7,12,18,22-24,26)$, we found that resistance to fluconazole 
TABLE 1. Frequency of $C$. glabrata as a cause of bloodstream infection in each of the nine U.S. Bureau of the Census regions

\begin{tabular}{lccr}
\hline \multicolumn{1}{c}{ Region } & $\begin{array}{c}\text { Total no. of } \\
\text { participating } \\
\text { centers }\end{array}$ & $\begin{array}{c}\text { Total no. of } \\
\text { Candida } \\
\text { bloodstream } \\
\text { isolates }\end{array}$ & $\begin{array}{c}\text { No. }(\%) \text { of } \\
\text { C. glabrata } \\
\text { isolates }\end{array}$ \\
\hline 1. Pacific & 48 & 439 & $81(18.5)$ \\
2. Mountain & 11 & 261 & $40(15.3)$ \\
3. West North Central & 21 & 302 & $57(18.9)$ \\
4. West South Central & 4 & 162 & $19(11.7)$ \\
5. East North Central & 12 & 376 & $99(26.3)$ \\
6. East South Central & 3 & 94 & $17(18.0)$ \\
7. New England & 3 & 83 & $31(37.3)$ \\
8. Mid-Atlantic & 13 & 736 & $138(18.8)$ \\
9. South Atlantic & 52 & 1,230 & $191(15.5)$ \\
& & 3,683 & $674(18.3)$ \\
Total & 167 & & \\
\hline
\end{tabular}

among bloodstream isolates of $C$. glabrata was much lower than $10 \%$ in seven of the nine U.S. census regions and in four of the six patient age groups (Table 2). Aside from the MidAtlantic and South Atlantic regions (regions 8 and 9, respectively), resistance was negligible among $C$. glabrata bloodstream isolates from pediatric patients and from individuals $>65$ years of age. Even in the region with the highest prevalence of $C$. glabrata (region $7 ; 37.3 \%$ ), the resistance rate was nil (Table 2).

Because we could not obtain fluconazole usage data for these regions, our study was not designed to examine the relationship between the emergence of $C$. glabrata as a fluconazole-resistant bloodstream infection pathogen and the level of fluconazole use (23). Although some investigators have found a strong association between fluconazole use and colonization and infection with $C$. glabrata $(1,26)$, others have not been able to corroborate those findings $(2-4,12)$. Baddley et al. (3) reported a stable rate of resistance to fluconazole of $10 \%$ among $C$. glabrata isolates despite a fluctuating prevalence of 18 to $31 \%$ and a steadily increasing usage of fluconazole over a 6-year period. Ásmundsdóttir et al. (2) found that although the usage of fluconazole in Iceland increased fourfold between 1990 and 1999, there was no increase in the prevalence of $C$. glabrata or in fluconazole resistance. Likewise, Nguyen et al. (12) found that C. glabrata was a prominent cause of breakthrough fungemia in amphotericin B-treated patients but not in those patients treated with fluconazole. Finally, if simply the selective pressure of fluconazole were responsible for both the emergence of $C$. glabrata and fluconazole resistance, one would expect that our data would reveal more fluconazoleresistant $C$. glabrata isolates in those regions with the highest prevalence of $C$. glabrata. Instead, the region with the highest C. glabrata prevalence had no fluconazole-resistant $C$. glabrata isolates.

The emergence of $C$. glabrata as a cause of bloodstream infection is therefore likely to be due to a complex set of factors, including changing demographics, antifungal usage, and an increasingly immunocompromised patient population $(4,18,22)$. As one example, changes in mucosal defenses with

TABLE 2. Fluconazole susceptibilities of C. glabrata bloodstream infection isolates by patient age group in each of the nine U.S. Bureau of the Census regions ${ }^{a}$

\begin{tabular}{|c|c|c|c|c|c|c|c|c|c|c|c|c|}
\hline \multirow{2}{*}{$\begin{array}{l}\text { Patient age } \\
\text { group (yr[s]) }\end{array}$} & \multirow{2}{*}{$\begin{array}{l}\text { No. } \\
\text { tested }\end{array}$} & \multirow{2}{*}{$\begin{array}{l}\text { Isolate } \\
\text { susceptibility } \\
\text { category }\end{array}$} & \multicolumn{10}{|c|}{$\%$ of S, S-DD, and R isolates (no. tested) in U.S. Census region: } \\
\hline & & & $1(52)$ & $2(28)$ & $3(51)$ & $4(17)$ & $5(80)$ & $6(17)$ & $7(27)$ & $8(117)$ & $9(170)$ & All (559) \\
\hline \multirow[t]{3}{*}{$\leq 1$} & 4 & $\mathrm{~S}$ & 100 & 100 & & & & & & 100 & 100 & 100 \\
\hline & & S-DD & 0 & 0 & & & & & & 0 & 0 & 0 \\
\hline & & $\mathrm{R}$ & 0 & 0 & & & & & & 0 & 0 & 0 \\
\hline \multirow[t]{3}{*}{$2-15$} & 9 & S & & 100 & & & 100 & & & 50 & 33 & 67 \\
\hline & & S-DD & & 0 & & & 0 & & & 50 & 33 & 22 \\
\hline & & $\mathrm{R}$ & & 0 & & & 0 & & & 0 & 33 & 11 \\
\hline \multirow[t]{3}{*}{$16-64$} & 306 & S & 45 & 75 & 77 & 86 & 58 & 50 & 50 & 58 & 47 & 56 \\
\hline & & S-DD & 41 & 25 & 23 & 7 & 30 & 25 & 50 & 28 & 41 & 32 \\
\hline & & $\mathrm{R}$ & 14 & 0 & 0 & 7 & 12 & 25 & 0 & 14 & 12 & 12 \\
\hline \multirow[t]{3}{*}{$65-74$} & 113 & $\mathrm{~S}$ & 40 & 33 & 79 & 100 & 64 & 0 & 57 & 67 & 71 & 64 \\
\hline & & S-DD & 60 & 33 & 21 & 0 & 36 & 100 & 43 & 6 & 26 & 29 \\
\hline & & $\mathrm{R}$ & 0 & 33 & 0 & 0 & 0 & 0 & 0 & 27 & 3 & 7 \\
\hline \multirow[t]{3}{*}{$75-80$} & 69 & S & 100 & 100 & 50 & 50 & 88 & & 83 & 71 & 62 & 68 \\
\hline & & S-DD & 0 & 0 & 42 & 50 & 12 & & 17 & 23 & 28 & 26 \\
\hline & & $\mathrm{R}$ & 0 & 0 & 8 & 0 & 0 & & 0 & 6 & 10 & 6 \\
\hline \multirow[t]{3}{*}{$>80$} & 58 & $\mathrm{~S}$ & 30 & 100 & 33 & & 38 & & 100 & 60 & 63 & 57 \\
\hline & & S-DD & 70 & 0 & 67 & & 50 & & 0 & 20 & 26 & 34 \\
\hline & & $\mathrm{R}$ & 0 & 0 & 0 & & 12 & & 0 & 20 & 11 & 9 \\
\hline \multirow[t]{3}{*}{ All } & 559 & S & 44 & 71 & 69 & 82 & 61 & 47 & 70 & 62 & 55 & 60 \\
\hline & & S-DD & 48 & 22 & 29 & 12 & 31 & 30 & 30 & 23 & 35 & 31 \\
\hline & & $\mathrm{R}$ & 8 & 7 & 2 & 6 & 8 & 23 & 0 & 15 & 10 & 9 \\
\hline
\end{tabular}

${ }^{a}$ Fluconazole susceptibility categories are as described in NCCLS document M27-A (11). S, the isolates are susceptible (MIC, $\leq 8 \mu \mathrm{g} / \mathrm{ml}$; S-DD, the isolates are susceptible in a dose-dependent manner (MIC, 16 to $32 \mu \mathrm{g} / \mathrm{ml}$ ); R, the isolates are resistant (MIC, $\geq 64 \mu \mathrm{g} / \mathrm{ml}$ ). 
age may underlie the observation that healthy older individuals with no exposure to fluconazole become colonized with $C$. glabrata (9). Fluconazole-naïve strains of $C$. glabrata may not demonstrate resistance to fluconazole; thus, bloodstream infection, when it occurs in individuals older than 70 years of age, may be more a function of changes in the ecology of the candidal flora with age than selection of $C$. glabrata due to drug pressure. Considerably more investigation is necessary before these complex issues are understood.

The relatively small number of isolates from several regions and age groups limits this study. In addition, we could not obtain complete data on several important patient-related factors that might have influenced the risk for C. glabrata or the risk for fluconazole resistance (e.g., severity of illness, device use, underlying disease, and antifungal use). Nonetheless, the overall size of this collection of C. glabrata bloodstream isolates does provide important descriptive information. We have provided the first U.S. regional surveillance data on bloodstream infection due to C. glabrata. This information may serve as the baseline for future studies regarding the prevalence and antifungal susceptibility of $C$. glabrata as a bloodstream pathogen.

We thank Linda Elliott for excellent support in the preparation of the manuscript.

The International Fungal Surveillance Program was supported in part by research grants from Bristol-Myers Squibb, Pfizer, and Schering-Plough.

We express our appreciation to all International Fungal Surveillance Program participants. Participating institutions that contributed to this study included the following: Christiana Care Health Services, Wilmington, Del. (L. Steele-Moore); Clarion Health Methodist Hospital, Indianapolis, Ind. (G. Denys); Henry Ford Hospital, Detroit, Mich. (C. Staley); Summa Health System, Akron, Ohio (J. R. Dipersio); Good Samaritan Regional Medical Center, Phoenix, Ariz. (M. Saubolle); Denver General Hospital, Denver, Colo. (M. L. Wilson); University of New Mexico Hospital, Albuquerque (G. D. Overturf); Northwestern Memorial Hospital, Chicago, Ill. (L. R. Peterson); University of Illinois at Chicago, Chicago (P. C. Schreckenberger); University of Iowa Hospitals and Clinics, Iowa City (G. V. Doern); Creighton University, Omaha, Nebr. (S. Cavalieri); Froedtert Memorial Lutheran Hospital-East, Milwaukee, Wis. (S. Kehl); Boston VAMC, Boston, Mass. (S. Brecher); Columbia Presbyterian Medical Center, New York, N.Y. (L. Lee); Long Island Jewish Medical Center, New Hyde Park, N.Y. (H. Isenberg); Strong Memorial Hospital, Rochester, N.Y. (D. Hardy); St. Jude Medical Center, Fullerton, Calif. (D. S. Koga, P. Wardell); Kaiser Regional Laboratory, Berkeley, Calif. (J. Fusco); Sacred Heart Medical Center, Spokane, Wash. (M. Hoffmann, D. Anderson); University of Washington Medical Center, Seattle (S. Swanzy); BarnesJewish Hospital, St. Louis, Mo. (P. R. Murray); Parkland Health \& Hospital System, Dallas, Tex. (P. Southern); The University of Texas Medical School, Houston, Tex. (A. Wanger); University of Texas Medical Branch at Galveston, Galveston, Tex. (B. Reisner); University of Louisville Hospital, Louisville, Ky. (J. Snyder); Carolinas Medical Center, Charlotte, N.C. (S. Jenkins); University of Virginia Medical Center, Charlottesville (K. Hazen); Pathology Medical Laboratories, San Diego, Calif. (D. A. Schwab); University of Utah Hospitals and Clinics, Salt Lake City (K. Carroll); Lahey Clinic, Burlington, Mass. (K. Chapin-Robertson); Geisinger Medical Center, Danville, Pa. (P. Bourbeau); Mount Sinai Medical Center, Miami Beach, Fla. (S. E. Sharp); Mount Sinai Medical Center, New York, N.Y. (I. Rankin); Hershey Medical Center, Hershey, Pa. (P. Appelbaum); UCLA Medical Center, Los Angeles, Calif. (D. Bruckner); NYSDOH, Albany, N.Y. (V. Chaturvedi); Cleveland Clinic Foundation, Cleveland, Ohio (G. Hall); VA Medical Center, Ann Arbor, Mich. (C. Kauffman); Harper Hospital, Detroit, Mich. (J. Sobel); Temple University, Philadelphia, Pa. (B. Suh); Westchester Medical Center, Valhalla, N.Y. (K. Van Horn); Chandler Hospital, Savannah, Ga. (A. Davis, L. Formby); St. Joseph
Hospital, Omaha, Nebr. (S. Cavalieri); St. Alexius Medical Center, Bismarck, N.Dak. (R. Baltzer, S. Ziemann); St. Mary's Hospital, Enid, Okla. (C. Williams, J. Word); Mercy Hospital, Bakersfield, Calif. (S. Eyherabide, S. Langenfeld); Western Pennsylvania Hospital, Pittsburgh (K. Gartner, T. Montgomery); Broward General Medical Center, Fort Lauderdale, Fla. (P. Johnson, J. Stone); Memorial Medical Center, Savannah, Ga. (M. McNally, M. Shapiro); Mercy Hospital Medical Center, Des Moines, Iowa (M. L. Davenport); Sioux Valley Hospital, Sioux Falls, S.Dak. (L. Docken, D. Ohrt); Immanuel Medical Center, Omaha, Nebr. (V. Oczki, G. Pullen); Maricopa Medical Center, Phoenix, Ariz. (J. Chapman, S. Gamble); Florida Hospital \& Medical Center, Orlando (H. Ferwerda, T. Otal, S. Hernandez); VA Medical Center, Palo Alto, Calif. (C. Valdon, G. Vigionese, C. Vyeda); St. John Mercy Medical Center, St. Louis, Mo. (J. Block, L. Meyer); St. Vincent Hospital and Health Center, Billings, Mont. (L. Temme, S. Skates); University Medical Center, Las Vegas, Nev. (J. Bingham, V. Leslie); United Medical Center, Cheyenne, Wyo. (S. Garner, C. Halverson); Walter O. Boswell Hospital, Sun City, Ariz. (J. Theis, V. Verhoern); Lutheran General Hospital, Park Ridge, Ill. (N. Bharani, C. Galaviz); Lexington VA Medical Center, Lexington, Ky. (T. Overman); Sentara Norfolk General Hospital, Norfolk, Va. (B. Greene, L. Howell); Baystate Medical Center, Springfield, Mass. (M. Gardner, M. Schulte); St. Mary's Medical Center, Langhorne, Pa. (P. Arsdale, H. Kroh); Beth Israel Medical Center, New York, N.Y. (M. Motyl); United Samaritans Medical Center, Danville, Ill. (M. Lampman, B. Morris, D. Page); Community Hospital of Indianapolis, Indianapolis, Ind. (P. Gielerak); Medical College of Virginia, Richmond (R. Wenzel); Parkview Medical Center, Pueblo, Colo. (L. Fairbanks); and Presbyterian Healthcare Services, Albuquerque, N.Mex. (J. Ferranti).

\section{REFERENCES}

1. Abi-Said, D., E. Anaissie, O. Uzun, I. Raad, H. Pinzcowski, and S. Vartivarian. 1997. The epidemiology of hematogenous candidiasis caused by different Candida species. Clin. Infect. Dis. 24:1122-1128.

2. Ásmundsdóttir, L. R., H. Erlendsdóttir, and M. Gottfredsson. 2002. Increasing incidence of candidemia: results from a 20 -year nationwide study in Iceland. J. Clin. Microbiol. 40:3489-3492.

3. Baddley, J. W., A. M. Smith, S. A. Moser, and P. G. Pappas. 2001. Trends in frequency and susceptibilities of Candida glabrata bloodstream isolates at a university hospital. Diagn. Microbiol. Infect. Dis. 39:199-201.

4. Baran, J., B. Muckatira, and R. Khatib. 2001. Candidemia before and after the fluconazole era: prevalence, type of species and approach to treatment in a tertiary care community hospital. Scand. J. Infect. Dis. 33:137-139.

5. Barry, A. L., M. A. Pfaller, S. D. Brown, A. Espinel-Ingroff, M. A. Ghannoum, C. Knapp, R. P. Rennie, J. H. Rex, and M. G. Rinaldi. 2000. Quality control limits for broth microdilution susceptibility tests of ten antifungal agents. J. Clin. Microbiol. 38:3457-3459.

6. Diekema, D. J., S. A. Messer, A. B. Brueggemann, S. L. Coffman, G. V. Doern, L. A. Herwaldt, and M. A. Pfaller. 2002. Epidemiology of candidemia: 3-year results from the Emerging Infections and the Epidemiology of Iowa Organisms study. J. Clin. Microbiol. 40:1298-1302.

7. Gumbo, T., C. M. Isada, G. Hall, M. T. Karafa, and S. M. Gordon. 1999. Candida glabrata fungemia: clinical features of 139 patients. Medicine 78: 220-227.

8. Kauffman, C. A. 2001. Fungal infections in older adults. Clin. Infect. Dis. 33: $550-555$.

9. Lockhart, S. R., S. Joly, K. Vargas, J. Swails-Wenger, L. Enger, and D. R. Soll. 1999. Defense against Candida carriage breakdown in the elderly. J. Dent. Res. 78:857-868.

10. Marr, K. A., K. Seidel, T. C. White, and R. A. Bowden. 2000. Candidemia in allogeneic blood and marrow transplant recipients: evolution of risk factors after adoption of prophylactic fluconazole. J. Infect. Dis. 181:309-316.

11. National Committee for Clinical Laboratory Standards. 1997. Reference method for broth dilution antifungal susceptibility testing of yeasts. Approved standard M27-A. National Committee for Clinical Laboratory Standards, Wayne, Pa.

12. Nguyen, M. H., J. E. Peacock, A. J. Morris, D. C. Tanner, M. L. Nguyen, D. R. Snydman, M. M. Wanener, M. G. Rinaldi, and V. L. Yu. 1996. The changing face of candidemia: emergence of non-Candida albicans species and antifungal resistance. Am. J. Med. 100:617-623.

13. Pfaller, M. A., S. A. Messer, R. J. Hollis, R. N. Jones, and D. J. Diekema. 2002. In vitro activities of ravuconazole and voriconazole compared with those of four approved systemic antifungal agents against 6,970 clinical isolates of Candida spp. Antimicrob. Agents Chemother. 46:1723-1727.

14. Pfaller, M. A., D. J. Diekema, R. N. Jones, S. A. Messer, R. J. Hollis, and the SENTRY Participants Group. 2002. Trends in antifungal susceptibility of Candida spp. isolated from pediatric and adult patients with bloodstream 
infections: SENTRY Antimicrobial Surveillance Program, 1997 to 2000 J. Clin. Microbiol. 40:852-856.

15. Pfaller, M. A., and D. J. Diekema. 2002. Role of sentinel surveillance of candidemia: trends in species distribution and antifungal susceptibility. J. Clin. Microbiol. 40:3551-3557.

16. Pfaller, M. A., and D. J. Diekema. 2002. 12 years of fluconazole in clinical practice: global trends in species distribution and fluconazole susceptibility of Candida bloodstream isolates. Clin. Microbiol. Infect., in press.

17. Rex, J. H., T. J. Walsh, J. D. Sobel, S. G. Filler, P. G. Pappas, W. E. Dismukes, and J. E. Edwards. 2000. Practice guidelines for the treatment of candidiasis. Clin. Infect. Dis. 30:662-678.

18. Safdar, A., V. Chaturvedi, B. S. Koll, D. H. Larone, D. S. Perlin, and D. Armstrong. 2002. Prospective, multicenter surveillance study of Candida glabrata: fluconazole and itraconazole susceptibility profiles in bloodstream, invasive, and colonizing strains and differences between isolates from three urban teaching hospitals in New York City (Candida Susceptibility Trends Study, 1998 to 1999). Antimicrob. Agents Chemother. 46:3268-3272.

19. Saiman, L., E. Ludington, M. Pfaller, S. Rangel-Frausto, R. T. Wiblin, J. Dawson, H. M. Blumberg, J. E. Patterson, M. Rinaldi, J. E. Edwards, R. P Wenzel, W. Jarvis, and the National Epidemiology of Mycosis Survey Study Group. 2000. Risk factors for candidemia in neonatal intensive care unit patients. Pediatr. Infect. Dis. J. 19:319-325.

20. Sanglard, D., F. Ischer, D. Calabrese, P. A. Majcherczyk, and J. Bille. 1999.
The ATP binding cassette transporter gene $C g C D R 1$ from Candida glabrata is involved in the resistance of clinical isolates to azole antifungal agents. Antimicrob. Agents Chemother. 43:2753-2765.

21. Sanglard, D., F. Ischer, and J. Bille. 2001. Role of ATP-binding-cassette transporter genes in high-frequency acquisition of resistance to azole antifungals in Candida glabrata. Antimicrob. Agents Chemother. 45:1174-1183.

22. Sanglard, D., and F. C. Odds. 2002. Resistance of Candida species to antifungal agents: molecular mechanisms and clinical consequences. Lancet Infect. Dis. 2:73-85.

23. Trick, W. E., S. K. Fridkin, J. R. Edwards, R. A. Hajjeh, R. P. Gaynes, and the National Nosocomial Infections Surveillance System Hospitals. 2002. Secular trend of hospital-acquired candidemia among intensive care unit patients in the United States during 1989-1999. Clin. Infect. Dis. 35:627-630.

24. Vazquez, J. A., L. M. Dembry, V. Sanchez, M. A. Vazquez, J. D. Sobel, C. Dmuchowski, and M. J. Zervos. 1998. Nosocomial Candida glabrata colonization: an epidemiologic study. J. Clin. Microbiol. 36:421-426.

25. White, T. C., K. A. Marr, and R. A. Bowden. 1998. Clinical, cellular, and molecular factors that contribute to antifungal drug resistance. Clin. Microbiol. Rev. 11:382-402.

26. Wingard, J. R., W. G. Merz, M. G. Rinaldi, C. B. Miller, J. E. Karp, and R. Saral. 1993. Association of Torulopsis glabrata infections with fluconazole prophylaxis in neutropenic bone marrow transplant patients. Antimicrob. Agents Chemother. 37:1847-1849. 